\title{
Performance Of Zycosoil- A Nano Material As An Additive With Bituminous Concrete Mix.
}

\author{
${ }^{1}$ Tirthankar Dam, ${ }^{2}$ Vinal Khambhayta, ${ }^{3}$ Daxesh Makwana, \\ ${ }^{4}$ Sanjay Kumar Jadav, ${ }^{5}$ Bala Raju Teppala, ${ }^{6}$ Prof. C.B. Mishra* \\ ${ }^{1,2,3,4}$ B. E. Students, ${ }^{5}$ M.E. Student, ${ }^{6}$ Associate Professor, Civil Engineering Department \\ BVM Engineering College, V. V. Nagar, Anand, India.
}

\begin{abstract}
Road sectors are the engines of growth for economy, employment and empowerment. Towns and cities have acted as focal points in the cultural landscape of India for nearlymillennia, though with some significant breaks in between. They continue to play a major role in India's emergence as a premier industrial and political power in the world. Owing to increases in household income, the demands for personalized vehicles have also increased. The booming trade in the commercial vehicle sector has changed the truck industry in India, and definitely for the betterment to meet the demands of industrial activities putting more pressure on VG 30 flexible roads, the effect is noted more significantly with variations in daily and seasonal temperatures contributing to high stresses affecting the flexible pavement. India is brimming with several bad roads be it the metro cities, the cities or the villages. Hence it is our major responsibility that the highway engineers and those associated to it can construct long-lasting roads. So that India can be at par with the developed countries of the world.

In order to cope up with the increasing trend of highly laden vehicles, new innovative materials needs to be utilized for highway construction. The present paper thus enlightens theprocedure to find out optimum bitumen content by Marshall Mix design method for BC mix which attains maximum stability by using innovative nanotechchemical material. To $5.4 \%$ optimum bitumen content for BC mix obtained in the laboratory investigations, required dosages of Zycosoil chemical in 0.02\%, 0.03\% and 0.04\% is added and changes in properties are recorded showing improved good results for the mix to be suggested for flexible pavement construction.
\end{abstract}

Keywords: Bituminous Concrete, Marshall Mix Design,Optimum Bitumen Content, Stability value, Zycosoil.

\section{Introduction}

India has a road network of over 4,689,842 kilometers $(2,914,133 \mathrm{mi})$ in 2013, the second largest road network in the world. At $0.66 \mathrm{~km}$ of roads per square kilometer of land, the quantitative density of India's road network is similar to that of the United States (0.65). However, qualitatively India's roads are a mix of modern highways and narrow, unpaved roads, and are being improved. As of 2011, 54 percent i.e. about 2.53 million kilometers of Indian roads were paved. Presently, as of April 2014, India has completed and placed in use over 22,400 kilometers of recently built 4 or 6-lane highways connecting many of its major manufacturing centers, commercial and cultural centers.

But one of the striking underlying facts is the condition of the roads. Since roads indirectly contribute to the economic growth of the country it is extremely essential that the roads are well laid out and strong. India is home to several bad roads be it the metropolitans, the cities or the villages.

In recent times there has been a sharp increase in population coupled with increase in highly laden commercial vehicles in limited road space with significant variations in daily, seasonal temperature and extreme environmental conditions posing pressure on roads thereby inducing more stresses on roads which needs innovative material to resist the stresses without any compromise with quality and performance. Design, construction and maintenance of roads are given prime importance in the development of the infrastructure of a country.

The principle of sustainability in the 21 st century dictates the need of conserving resources for highway construction. Durability is the key parameter of acceptable serviceability. Zycosoil chemical nanotechnology is a patented breakthrough to address these issues at an economic cost. Initially in the project, an attempt has been made to identify the engineering properties of materials and study the impacts of Zycosoil on VG 30 bituminous mixes with and without it, according to the standards as specified in MoRTH.

\section{Literature}

2.1 Bala Raju Teppala and C.B. Mishra (2014): In this paper, it is stated that the burgeoning urban population of India with rapid rise in industrialization coupled with high increase of road vehicles engaging in rapidly 
expanding cities to fit the developmental needs of the economy demands good quality of roads to cope up the increasing pressure of road traffic. It becomes the responsibility of researchers, scientists, contractors to improve the riding quality while maintaining the economy for the country like ours. In this paper, initially the investigations are carried out to determine engineering properties of locallyavailable crushed stones, fillers and 60/70 grade bitumen for mix design. Marshall Method of mix design for DBM (grade 1) was adopted to find out the optimum bitumen content. In order to arrive at homogenous mix with required standards, VG 30 bituminous mix with obtained $4.25 \%$ optimum bitumen content is taken into consideration for Modified Marshall Mix design by addition of $0.03 \%, 0.04 \%$ and $0.06 \%$ dosage of Zycosoil chemical is prepared and tested to determine the key properties as per the codal provision.

2.2Anil Kumar and Vijaya Kumar H (2014):They have given prime importance to design, construction and maintenance of roads in the development of the infrastructure of a country. High traffic intensity in terms of overloaded commercial vehicles, significant variations in daily and seasonal temperature and extreme environmental conditions are responsible for early development of distress symptoms like rutting, cracking, bleeding, and shoving and moisture damage of bituminous surfacing. The development of distresses in the pavements with the conventional mixes reveals the need for use of improved materials and techniques for design specifications based on performance tests. The performance tests are those tests which simulate the field conditions and measure the response of the bituminous mix in terms of stress, strain and deflection. The present investigation was carried out to propose the use of chemical. Chemical were mixed to bituminous concrete by wet process to get modified mix. Marshall Method of mix design was adopted to find out the optimum bitumen content. Marshall specimen were prepared for bitumen content of 5.0,5.5,6.0,6.5 and 7.0 per cent by weight of aggregate with $0.1 \%$ of chemical by weight of bitumen. Bulk density, Marshall Stability, Flow, Air Voids (Vv), Voids in Mineral Aggregates (VMA), voids filled with bitumen (VFB), Retained stability, Indirect Tensile Strength and Tensile Strength Ratio (TSR), Stripping, Fatigue life and deformations were determined and compared with neat bituminous concrete mixes. The Marshall Stability, Retained stability, Indirect Tensile Strength (ITS), Tensile Strength ratio, fatigue life values for modified mix was increased, similarly stripping of bitumen and rutting deformation decreased considerably as compared to conventional mix.

2.3Remadevi M., Anjali G. Pillai, , Elizabeth Baby George, Priya Narayanan, Sophiya Sunny (2014)Their proposed work presents the studies on stability, flow and volumetric properties of fibre reinforced bituminous concrete in comparison with the properties of conventional bituminous concrete. Marshall's stability tests were conducted to determine the optimum binder content. By varying the amount of $10 \mathrm{~mm}$ polypropylene fibres $(4 \%, 6 \%, 8 \%$ and $10 \%$ by weight of bitumen), optimum fibre content was obtained. The results indicate that the addition of PP fibres increases the stability but decreases the flow value.

2.4Sangita et al. (2011): The effect of waste polymer modifier (nitrile rubber and polythene) on various mechanical properties of the bituminous concrete mixtures was evaluated. Various test results on 60/70 bitumen and aggregate satisfied the specified limits. Marshall Stability and retained stability tests confirmed the optimum WPM content to be $8 \%$. The WPMB mix containing $8 \%$ WPM showed significant improvements in various properties of the bituminous concrete mixture. The higher values of Marshall Stability and retained stability indicated increased strength and low moisture susceptibility.

\section{Materials And Methods}

Crushed stone aggregate (coarse, fine and filler)is of paramount importance for flexible pavement as the load is transferred from stone to stone;also key interlocking is of vital credibility in the gradation of mix design after the investigations of physical requirements for bituminous concrete mix. The material is obtained from Valsad.

\section{Laboratory Tests}

Physical Requirements for Coarse Aggregate for bituminous concrete (As per MoRTH Table: 500-8)

\begin{tabular}{|c|c|c|c|c|}
\hline Sr. No & Property & Test & Specification & Test Result \\
\hline 1 & Cleanliness (dust) & Grain size analysis & Max $5 \%$ passing 0.075 IS-Sieve & $3.00 \%$ \\
\hline 2 & Particle shape & $\begin{array}{l}\text { Flakiness \& Elongation } \\
\text { Indices (Combined) }\end{array}$ & $30 \% \operatorname{Max}$ & $19.61 \%$ \\
\hline 3 & Strength & Aggregate Impact Value(AIV) & $27 \% \operatorname{Max}$ & $8.41 \%$ \\
\hline \multirow{3}{*}{4} & \multirow{3}{*}{ Durability } & \multicolumn{3}{|l|}{ Soundness } \\
\hline & & Magnesium sulphate & Max $18 \%$ & $0.68 \%$ \\
\hline & & Sodium sulphate & Max $12 \%$ & $0.57 \%$ \\
\hline 5 & Stripping & $\begin{array}{l}\text { Coating and } \text { Stripping } \\
\text { Bitumen Aggregate Mixtures }\end{array}$ & Min. Retained Coating $95 \%$ & $96 \%$ \\
\hline 6 & Atterberg's & Plasticity Index & $4 \% \mathrm{Max}$ & Non-Plastic \\
\hline
\end{tabular}


Performance Of Zycosoil-A Nano Material As An Additive With Bituminous Concrete Mix.

\begin{tabular}{|l|l|l|l|l|}
\hline & $($ As per 507.2.3) & & \\
\hline 7 & Water absorption value & Water absorption value & $2 \%$ Max & $1.27 \%$ \\
\hline
\end{tabular}

Table - 1

Properties of Aggregates

\begin{tabular}{|l|l|l|l|l|l|}
\hline Sr.No. & Size of Aggregate & Aggregate Proportions & $\begin{array}{l}\text { Bulk } \\
\text { Specific Gravity }\end{array}$ & Apparent Specific Gravity & Water Absorption \\
\hline 1 & $12-6 \mathrm{~mm}$ & $35 \%$ & 2.854 & 2.956 & 1.21 \\
\hline 2 & $6 \mathrm{~mm}$ down & $63 \%$ & 2.850 & 2.463 & 1.33 \\
\hline 3 & Filler & $2 \%$ & 2.650 & - & - \\
\hline
\end{tabular}

Table -2

The aggregate gradations are the key parameters as it influences the performance of pavement layer and is to be carried out before mix design. For this purpose sieve analysis of aggregate has been done having size $19 \mathrm{~mm}, 13.2 \mathrm{~mm}, 9.5 \mathrm{~mm}, 6 \mathrm{~mm}$ and stone dust. Grading requirement of BC for this study should satisfy the MORTH requirement.

The graph shows the upper limit, obtained value and lower limit (as shown in Fig. 1).

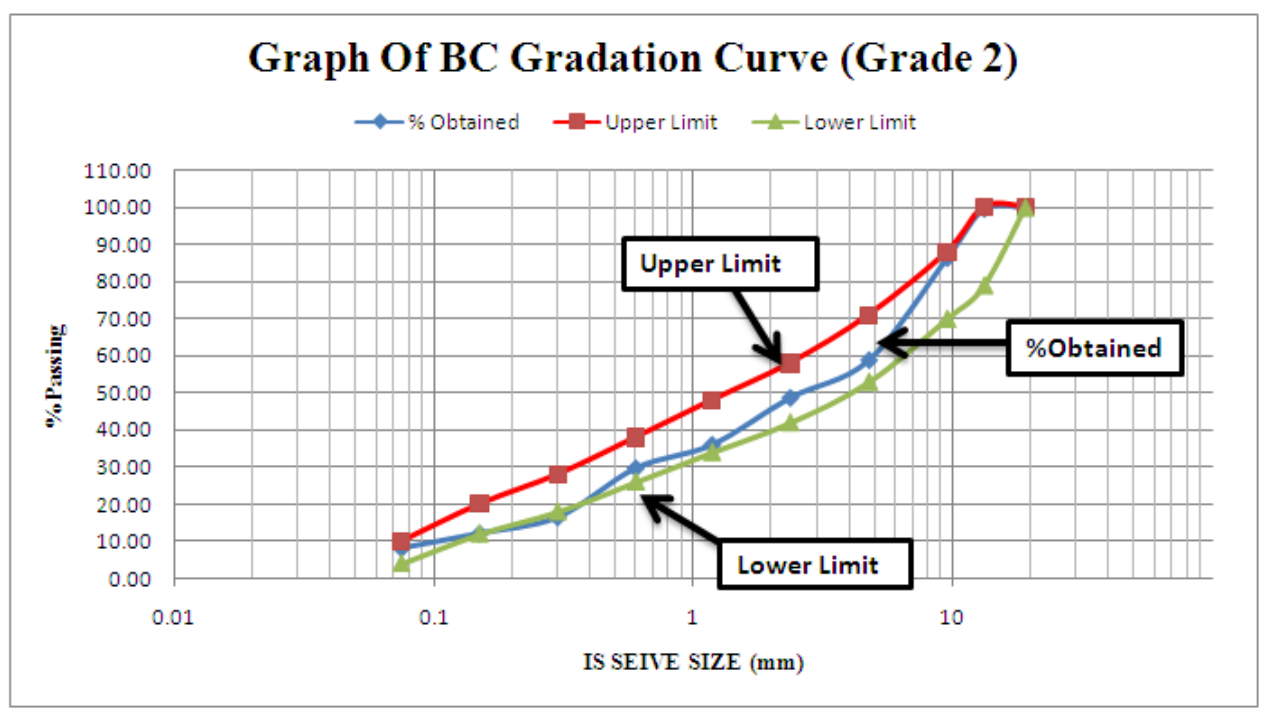

Figure.1- Graph of BC Gradation Curve (Grade 2)

\section{VG 30}

VG 30 bitumen is suggested for heavy density corridors having wide variety of loads. The bitumen possess excellent adhesive and bonding properties with aggregates, resists moisture to a great extent, resistance to mild acids and alkali too. It has low cost and thus this grade of bitumen is taken into consideration in our work.

\section{Zycosoil As Modifier}

Zycosoil is a water soluble compound that forms water clear solution. Zycosoil reaction leads to the permanent nano siliconization of the surfaces by converting the water loving silanol groups to water repellent siloxane bonds. The Si-O-Si siloxane bond is nature's strongest bond and lasts longer.Zycosoil's reactive bonding ability with the aggregates and asphalt helps to almost eliminate stripping of aggregates.Zycosoil in suitable dosages of $0.02 \%, 0.03 \%$ and $0.04 \%$ should be added directly by weight of binder and blended to proper mixing at $170^{\circ} \mathrm{C}$. The figure $2 \& 3$ shows the mechanism of soil and aggregate surface structure with and without Zycosoil. 


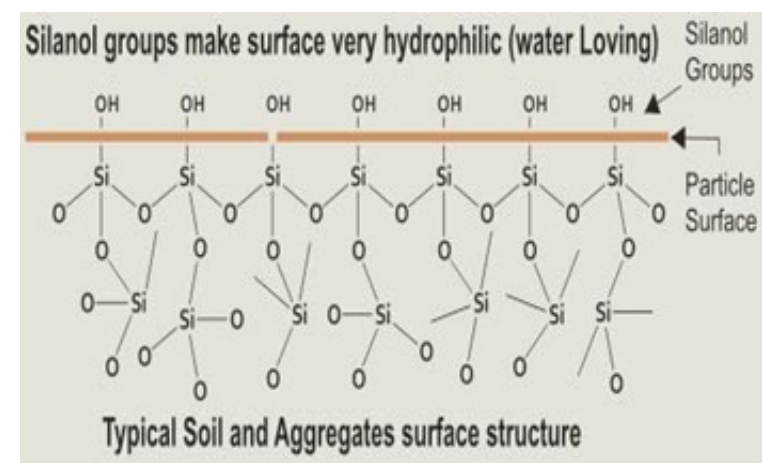

Figure.2- Soil and Aggregate structure before adding Zycosoil Zycosoil

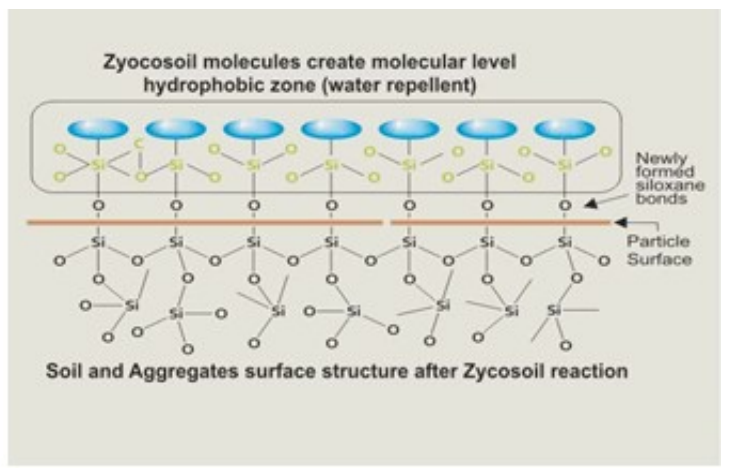

Figure.3- Soil and Aggregate structure after adding

Summary of test results of VG 30 grade bitumen with and without Zycosoil

\begin{tabular}{|l|l|l|l|l|l|l|}
\hline $\begin{array}{l}\text { Characteristics of } \\
\text { tests }\end{array}$ & VG 30 & $\begin{array}{l}\text { VG 30 +0.02 } \\
\text { \%Zycosoil }\end{array}$ & $\begin{array}{l}\text { VG 30 +0.03 } \\
\text { \%Zycosoil }\end{array}$ & $\begin{array}{l}\text { VG 30 +0.04 } \\
\text { \%Zycosoil }\end{array}$ & Min. Limit & Code \\
\hline Penetration $(\mathrm{mm})$ & 67 & 65.67 & 62 & 59.67 & $50-70$ & IS 1203 \\
\hline Softening point $\left(\mathrm{C}^{\circ}\right)$ & 53.5 & 54.7 & 55.6 & 57 & Min 47 & IS 1205 \\
\hline Ductility (cm) & 90 & 82 & 84 & 85 & Min 40 & IS 1208 \\
\hline $\begin{array}{l}\text { Absolute Viscosity at } \\
60\left(\mathrm{C}^{\circ}\right)\end{array}$ & 2478 & 2462 & 2457 & 2451 & $\begin{array}{l}\text { Min 2400 } \\
\text { poise }\end{array}$ & $\begin{array}{l}\text { IS } \\
(2 \text { nd part })\end{array}$ \\
\hline Stripping Test & 96 & 97 & 99 & 99 & Min 95\% & IS 6241 \\
\hline
\end{tabular}

Table - 3

VI. Marshall Stability Test for BCmix design grade - 2

This test has been carried out to determine the Optimum Binder content for $\mathrm{BC}$ mixes. Initially for $\mathrm{BC}$ grade 2, gradation of aggregates is carried out as per MoRTH specification and specimens are prepared with varying bitumen content. The properties incorporated with the tests which are stability, flow value, bulk specific gravity, air voids, voids filled with bitumen and voids in mineral aggregate are evaluated.The optimum binder content is worked out as $5.4 \%$ for BC Mix Design grading-2

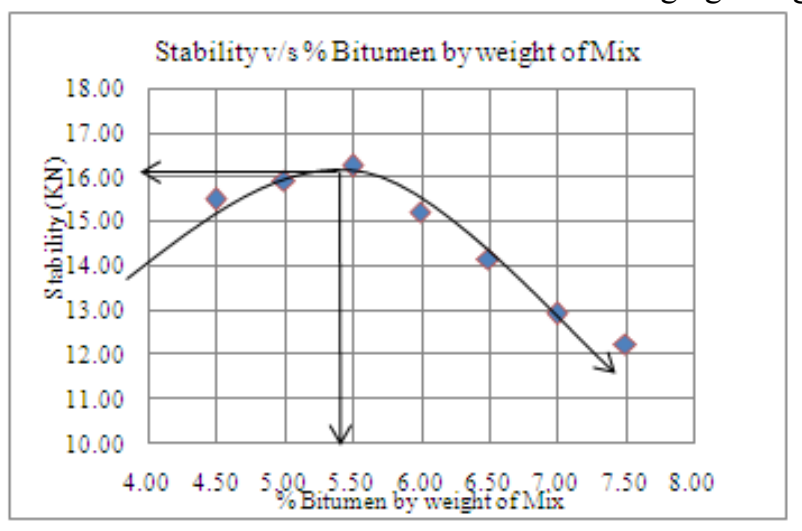

Figure.4- Marshall Stability v/s Bitumen Content

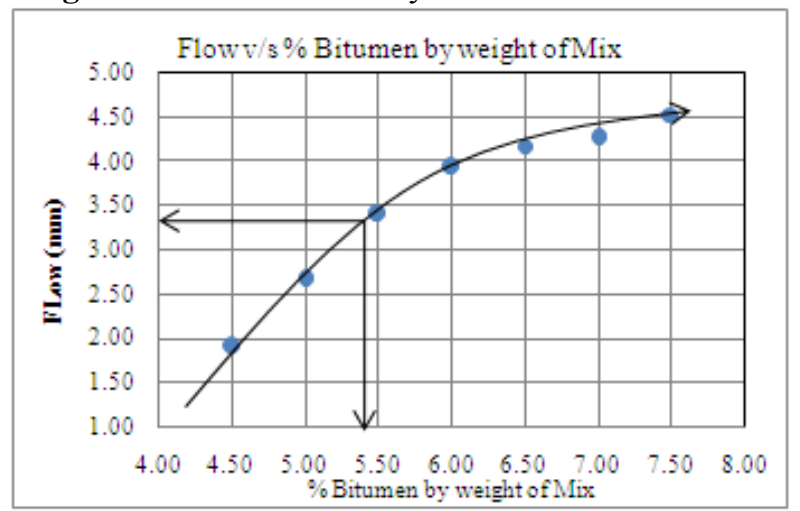

Figure.6- Marshall Flow v/s Bitumen Content

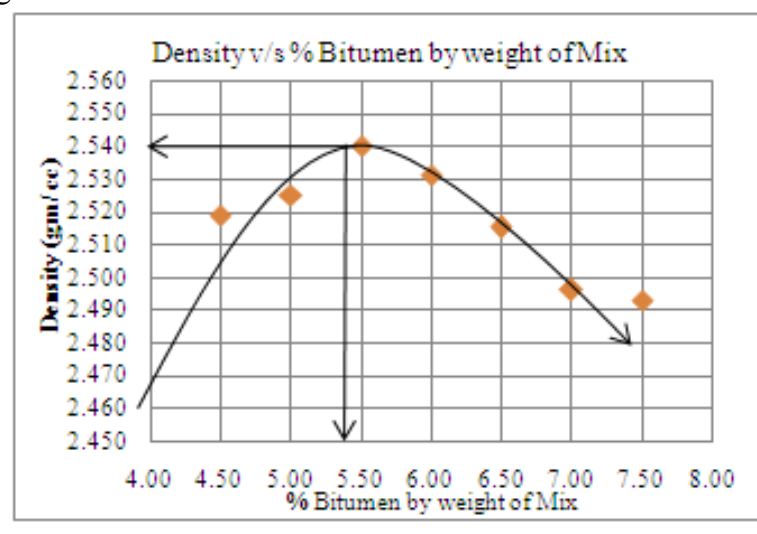

Figure.5- Bulk Density v/s Bitumen Content

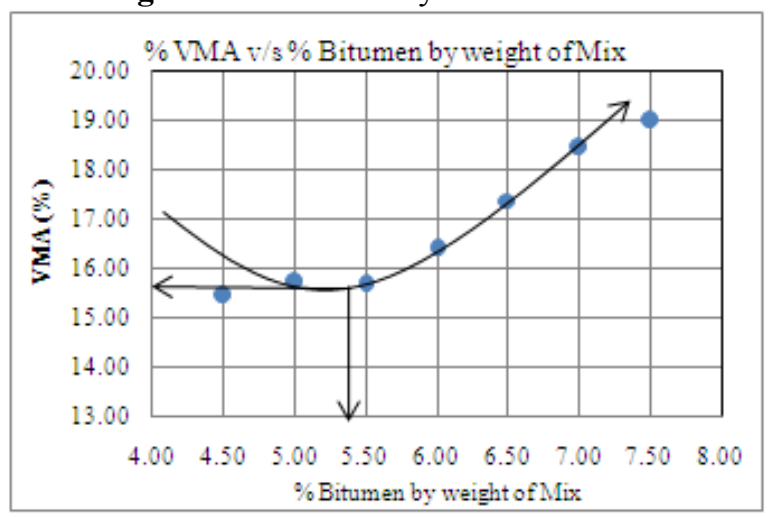

Figure.7- Voids in Mineral Aggregates v/s Bitumen Content 


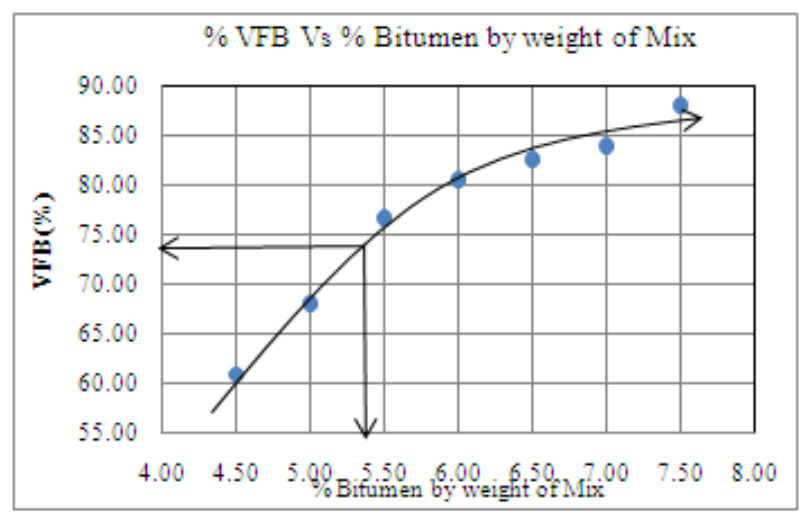

Figure.8- Voids Filled with Bitumen v/s Bitumen Content

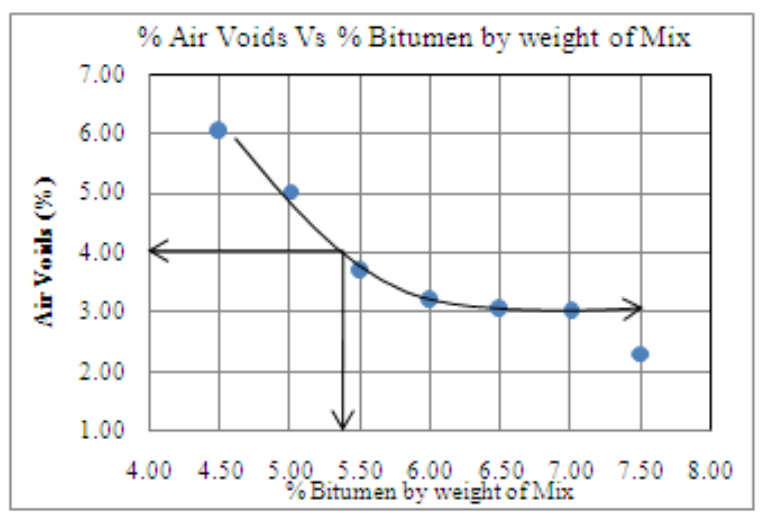

Figure.9- Air Voids v/s Bitumen Content

For various individual mixes a separate Marshall Mix design is carried out to find out the average OBC value to fulfil the required standards. To ensure a durable mix, the optimum bitumen content obtained is $5.4 \%$ for maximum stability and specified percent air voids and is taken into consideration for Modified Marshall mix design with and without addition of $0.02 \%, 0.03 \%$ and $0.04 \%$ dosage of Zycosoil chemical as an additive at temperature $175^{\circ} \mathrm{C}$ to compare properties by confirmatory test.

\begin{tabular}{|l|l|l|l|l|l|l|}
\hline Abstract of Marshal Mix Design Test Values (confirmatory test) & $\begin{array}{l}\text { Unit Weight } \\
\text { in gm/cc }\end{array}$ & Flow in mm & Air Voids in \% & VMA in \% & VFB in \% \\
\hline $\begin{array}{l}\text { Bitumen content by weight } \\
\text { of total mix \% }\end{array}$ & Stability (KN) & 2.534 & 1.90 & 4.04 & 15.76 & 74.36 \\
\hline $5.4 \%$ & 15.51 & 2.535 & 2.67 & 4.01 & 15.74 & 74.50 \\
\hline $0.02 \%$ Zycosoil & 15.92 & 2.533 & 3.40 & 4.08 & 15.80 & 74.15 \\
\hline $0.03 \%$ Zycosoil & 16.26 & 2.535 & 3.93 & 4.02 & 15.74 \\
\hline $0.04 \%$ Zycosoil & 15.21 & 74.49 & \\
\hline
\end{tabular}

Table -4

\section{ASTM 3625 Boiling Test}

Homogeneous test samples are prepared of VG 30 grade at $175^{\circ} \mathrm{C}$. Zycosoil chemical has the potential to change the surface chemistry of binding with aggregates. Zycosoil in required doses of $0.02 \%, 0.03 \%$ and $0.04 \%$ is added in melted asphalt binder to obtain a homogeneous mix. Standard procedure is adopted to prepare and test samples (Regular \& with Zycosoil) at $100^{\circ} \mathrm{C}$ and varied time as per norms.

\begin{tabular}{|c|c|c|c|c|}
\hline Test Sample at $100^{\circ} \mathrm{C}$ & $10 \mathrm{~min}$ & $30 \mathrm{~min}$ & 1 hour & 6 hour \\
\hline $5.4 \%$ asphalt binder by weight of $\operatorname{mix}($ without Zycosoil) & $96 \%$ & $96 \%$ & $96 \%$ & $95 \%$ \\
\hline $5.4 \%$ asphalt binder containing Zycosoil $(0.02 \%)$ by weight of mix & $97 \%$ & $97 \%$ & $97 \%$ & $96 \%$ \\
\hline $5.4 \%$ asphalt binder containing Zycosoil $(0.03 \%)$ by weight of mix & $100 \%$ & $100 \%$ & $100 \%$ & $99 \%$ \\
\hline $5.4 \%$ asphalt binder containing Zycosoil $(0.04 \%)$ by weight of mix & $100 \%$ & $100 \%$ & $99 \%$ & $99 \%$ \\
\hline
\end{tabular}

Table -5 Specification : $<95 \%$ Fails

\section{Conclusions} codal practice:

Following conclusions are derived based on laboratory investigations keeping in aspect procedures of

It has been noted that there is a decrease in penetration value with the addition of Zycosoil as chemical with VG 30 mix as the chemistry has changed the property, as stiffness has increased, enhanced condition of temperature susceptible is noted thereby increasing the workability of bituminous mix. As the bitumen is ductile and fulfils the standard criteria, the coating of aggregates is better.

The presence of VG 30 modification is seen with $0.03 \%$ dosage of Zycosoil chemical and this change is associated with moisture susceptibility test (Boiling point test). As Zycosoil is silane based additive it minimizes the moisture damage as a coating of bitumen is formed around the aggregate. In presence of water too it acts as an active adhesive preventing stripping. This will increase the life of pavement. Also there is an enhanced marginal difference seen in volumetric properties compared to VG 30 bituminous concrete mix design without Zycosoil and satisfies the specifications laid down in codal provision.

Proper gradation of aggregates for durable flexible pavement coupled with good compaction are of utmost importance to reduce the air void content of bituminous concrete mix pavements whichhave been able to show repeated improvementin moisture resistance owing to packing mechanism and enhancing the shear resistance of mix. In presence of water too it acts as an active adhesive preventing stripping. 


\section{References}

[1] Bala Raju Teppala and C.B. Mishra(2014) Performance Evaluation of VG 30 Paving mix with and without Zycosoil Chemical Additive

[2] Anil Kumar S and Vijaya Kumar H (2014) Fatigue Behavior of Chemically Treated Bituminous Concrete Mix International Journal of Research (IJR) Vol-1, Issue-6, July 2014

[3] Remadevi M., Anjali G. Pillai, , Elizabeth Baby George, Priya Narayanan, Sophiya Sunny - Study of Fibre Reinforced Bituminous Concrete,International Journal of Engineering Research and Development. Volume 10, Issue 4 (April 2014), PP.49-56

[4] Sangita, TabrezAlam Khan, Sabina \& D.K. Sharma - Effect of waste polymer modifier on the properties of bituminous

[5] IS: 1202- 1978, Methods for testing tar and bituminous materials: determination of specific gravity.

[6] IS: 1203-1978, Methods for testing tar and bituminous materials: determination of penetration.

[7] IS: 1205-1978, Methods for testing tar and bituminous materials: determination softening point.

[8] IS: 1206- 1978, Methods for testing tar and bituminous materials: determination of viscosity.31. 32.

[9] IS: 2386 (Part 1) - 1963, Methods of test for Aggregates for concrete: Particle size and shape.

[10] IS: 2386 (Part 3) - 1963, Methods of test for Aggregates for concrete: specific gravity, density, voids, absorption and bulking.

[11] IS: 2386 (Part 4) - 1963, Methods of test for Aggregates for concrete: Impact value and Abrasion value.

[12] Ministry of Road Transport and Highways (MoRTH) Appendix 5 Anti-Stripping agents used for Bituminous Materials and Mixes.

[13] S.K. Khanna and Dr. C.E.G. Justo, Highway Engineering Published by Nem Chand \& Bros. (Eighth Edition-2001)

[14] http://www.zydexindustries.com 